\title{
Examples of Application of Exergy Analysis for the Evaluation of Ecological Effects in Thermal Processes*
}

\author{
Wojciech Stanek $^{* *}$ \\ Institute of Thermal Technology, Silesian University of Technology, Gliwice, Poland \\ wojciech.stanek@polsl.pl
}

\begin{abstract}
Unfavourable influence of human activity on the natural environment can be divided into two groups: depletion of limited non-renewable resources and rejection of harmful substances. The depletion of non-renewable resources should be minimized to keep them for generations which are yet to come (sustainable development). Exergy can be applied as a measure of the quality of natural resources. The influence of human activities on the depletion of natural resources can be evaluated by means of the calculus of cumulative consumption of exergy of non-renewable natural resources (thermo-ecological cost). This paper presents selected applications and basic notions of the theory of thermo-ecological cost developed by Szargut.
\end{abstract}

\section{Keywords: Exergy; non-renewable resources depletion; sustainability; thermo-ecological cost.}

\section{Introduction}

Modern society is increasingly dependent on mineral and fossil, non-renewable energy sources. The depletion of natural non-renewable resources is directly proportional to the level of energy consumption. Energy is used everywhere, for transport, heating, lighting, as well as for industry and agriculture. From the economic point of view the increase in consumption levels, and for that matter in energy production, is a starting point for further development. The history of civilization has been marked by occurrence of the patterns of growth and decline. Some of these processes have been gradual, going on for centuries and others have been rapid, endangering the existence of whole populations. Not only wars and natural disasters, but also overpopulation and economic disruption combined with local natural resources exhaustion brought the collapse of many civilizations. The act of Easter Island's deforestation, the depletion of fresh water in Central America, and the depletion of agricultural area in SouthEast Asia are some of many examples of anthropogenic impact on the natural environment.

At present, the symptoms of depletion of natural resources can be also observed. It results in the increase of prices of primary energy carriers. Some experts state that in the future non-renewable resources can be replaced by the renewable ones.

However, sober thinking leads to the conclusion that our economy will depend on the non-renewable natural resources- fossil fuels. For this reason we should minimize the depletion of fuel resources. The economic criterion is opposite to this statement. Still, to optimize design and operation of different systems, basic economic criterion is used. However, the ecological criterion should become more important in order to ensure a long term and sustainable source of energy supplies that will help to reduce the environmental impact and to satisfy growing energy demand.

\section{Concept of Thermo-Ecology}

Fig.1 presents schematically a simplified diagram of a manufacturing process chain.

Final production phase is preceded with so-called intermediate production phase delivering semi-finished products to the main process. Final manufacturing phase delivers products or systems that are used or operate according to their life-time. Then, they can be decommissioned and some parts can be recycled and used in the production cycle again. Analyzing backwards nets of interconnected processes, we always reach a preliminary stage which is extraction of resources from nature, even if some of processes are based on renewable resources. The interconnections between processes or between a process and the environment are represented by flows of $\mathrm{M}$ materials, E-energy, B-by products, T-transportation needs, and H-harmful substances. The aim of thermo-ecology is to express a total expenditure resulting from these flows, and to express them as a consumption of natural resources taken from the environment in a common unit, while assuming a different quality of/for different resources. As different resources and products are consumed in each of the mentioned steps of a power plant's operating lifetime, we have to take into consideration a common measure that allows us to compare all of these unfavourable effects.For this purpose we can apply exergy (Finneveden \& Ostlund, 1997; Sciubba, 2001; Szargut, Ziebik, \& Stanek, 2002; Szargut, 2005; Valero \& Botero, 2002; Wall, 2001).

\subsection{Thermo-Ecological Cost}

According to J. Szargut (Szargut, Ziebik, \& Stanek, 2002; Szargut, 2005) the thermo-ecological cost (TEC) is defined as a cumulative consumption of non-renewable exergy connected with the fabrication of a particular product including additionally the consumption resulting from the necessity of compensation of environmental losses caused by the rejection of harmful substances to the environment. The index of operational thermo-ecological

*This paper is an updated version of a paper published in the ECOS'10 proceedings. It is printed here with permission of the authors and organizers. 


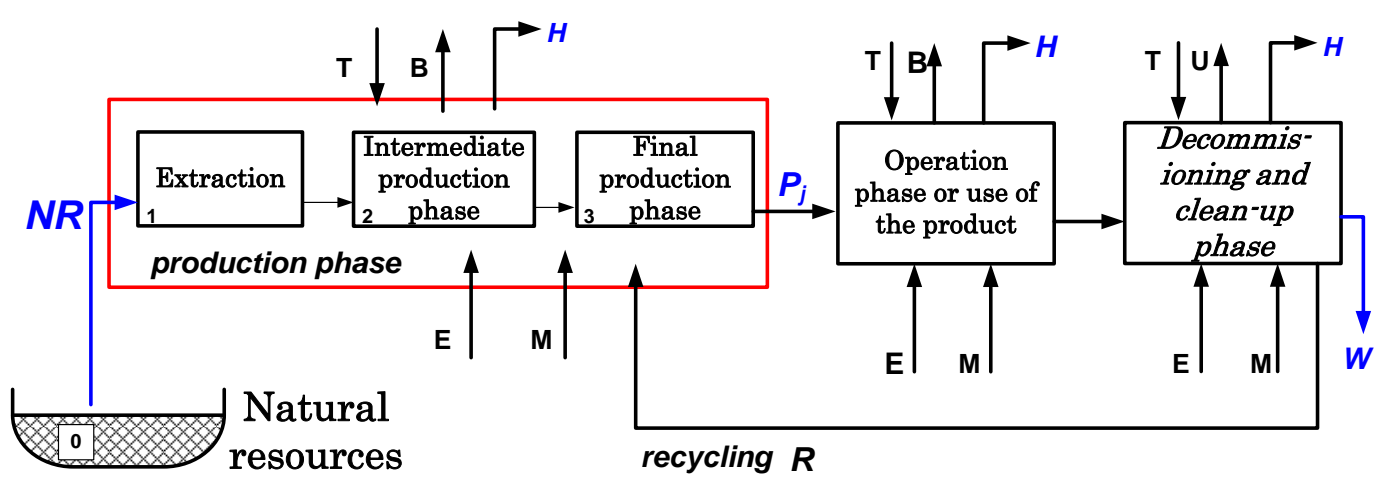

Figure 1. Diagram of production chain.

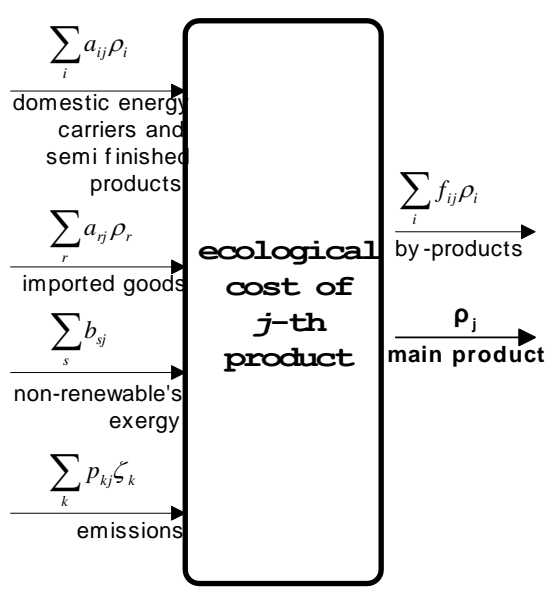

Figure 2. Balance of thermo-ecological cost.

cost can be determined by solving a set of thermoecological cost balance presented in Fig. 2.

The equation of the balance of thermo-ecological cost takes the following form:

$$
\rho_{j}+\sum_{\mathrm{i}}\left(\mathrm{f}_{\mathrm{ij}}-\mathrm{a}_{\mathrm{ij}}\right) \rho_{\mathrm{i}}-\sum_{\mathrm{r}} \mathrm{a}_{\mathrm{rj}} \rho_{\mathrm{r}}=\sum_{\mathrm{s}} \mathrm{b}_{\mathrm{sj}}+\sum_{l} z_{l j} \sigma_{l}+\sum_{\mathrm{k}} \mathrm{p}_{\mathrm{kj}} \zeta_{k}
$$

This set should comprise all the branches of domestic economy. However, it would be difficult to solve such a problem. For this reason in practical calculations only strongly connected production processes are taken into account (Stanek, 2001). In the equation set of the type (1) the imported goods, as well as by-products represent surplus of unknown values. For this reason the calculations basing on the procedure presented in Fig. 2 require the need of an iterative process. In the practical calculations the iterative algorithm described in detail in (Stanek, 2001) and (Stanek, 2009) has been applied. The results of calculations of the thermo-ecological cost have been presented in detail for example in (Stanek, 2001; Szargut, Ziebik, \& Stanek, 2002; Szargut \& Stanek, 2007; Stanek, 2009).

In the case of renewable products, only the external products are introduced into the algorithm, while the specific exergy $b_{s}$ should not be introduced. For instance, considering biomass, the exergy of biomass should not be taken into account in the balances of type (1). But there are of course other non-renewable requirements resulting from processing and delivering of biomass: fuel for transporting biomass, fuel for biomass cutting machines, fuel for biomass drying systems, etc. Only the non-renewable exergy is taken into account in Eqs. set of TEC (1). Whereas in the case of non-renewables (eg. coal) additionally the specific exergy of this fuel is taken into account. In this case it is a measure of the thermodynamic/environmental quality of this nonrenewable good. For the mentioned reason the presented method is an objective and unequivocal criterion based on common physical laws. This method can be applied for products based on both renewable and non-renewable resources. Moreover, using this method also the TEC of such products as services can be evaluated.

It is worth to introduce an index of sustainability into the thermo-ecological cost analyses:

$r_{i}=\frac{\rho_{i}}{b_{i}}$

Such an index expresses the ratio of thermo-ecological cost of the useful $i^{\text {th }}$ product which is related to its specific exergy. The lower the index of sustainability, the better the obtained results are from an ecological point of view. We pay less of cumulative exergy of natural resources per unit of exergy of particular useful products. Undertaken actions for decreasing the sustainability index should be, of course, justifiable from the economic point of view.

Tables 1 and 2 present calculation results of thermoecological cost, as well as the sustainability index of the main fuels utilized within the domestic energy management and selected semi-products.

Table 1. Thermo-ecological cost of fuels.

\begin{tabular}{|c|c|c|c|}
\hline Energy carrier & $\begin{array}{c}b_{\mathrm{ch}} \\
\mathrm{MJ} / \mathrm{um}\end{array}$ & $\begin{array}{c}\rho \\
\text { MJ/um }\end{array}$ & $\begin{array}{c}r \\
\mathrm{MJ} / \mathrm{MJ}\end{array}$ \\
\hline Hard coal $^{1}$ & 26.2 & 27.2 & 1.04 \\
\hline Coke $^{1}$ & 31.8 & 46,1 & 1.45 \\
\hline Natural gas ${ }^{2}$ & 821.6 & 710.3 & 0.86 \\
\hline Natural gas $^{2}$ (domestic) & 821.6 & 835.7 & 1.02 \\
\hline Natural gas ${ }^{2}$ (import) & 821.6 & 619.9 & 0.75 \\
\hline Coke-oven gas $^{2}$ & 380.0 & 356.5 & 0.94 \\
\hline
\end{tabular}

)$\left.^{1} \mathrm{um}=\mathrm{kg}, \quad\right)^{2} \mathrm{um}=\mathrm{kmol}, \mathrm{b}_{\mathrm{ch}}-$ specific chemical exergy 
Table 2. Thermo-ecological cost of semi-products.

\begin{tabular}{lrrr}
\hline Energy carrier & \multicolumn{1}{c}{$\begin{array}{c}b_{\text {ch }} \\
\text { MJ/um }\end{array}$} & $\begin{array}{c}\rho \\
\text { MJ/um }\end{array}$ & $\begin{array}{c}r \\
\text { MJ/MJ }\end{array}$ \\
\hline Pig iron $^{1}$ & 8.7 & 28.7 & 3.30 \\
Oxygen $^{2}$ & 3.4 & 87.0 & 25.7 \\
Cement $^{1}$ (Portland) $^{\text {Amonia }}{ }^{1}$ & 1.8 & 10.8 & 6.00 \\
Sulphur acid $^{1}$ & 19.8 & 40.5 & 2.04 \\
Aluminium $^{1}$ & 1.7 & 14.5 & 8.53 \\
& 33.0 & 190.6 & 5.77
\end{tabular}

)$\left.^{1} \mathrm{um}=\mathrm{kg}, \quad\right)^{2} \mathrm{um}=\mathrm{kmol}$

Results presented in Table 1 confirm that among fuels most commonly used in domestic energy management, coke is characterized by a relatively high value of thermoecological cost and sustainability index. For this reason the utilization of coke should be minimized as much as possible.

Table 2 shows that semi-products are burdened by relatively high values of the sustainability factor. Mainly, it results from the accumulation of fuel consumption in the inter-connected processes that lead to the semi-products. Among the products included in Table 2, oxygen is burdened by the highest value of factor $r$. It should be taken into account, for example, while considering the process of oxy-combustion.

\subsection{Life cycle assessment (LCA)}

The Thermo Ecological Life Cycle Assessment (TECLCA), based on the methodology described in previous section, comprises the following phases:

1. Construction Phase encompasses project, extraction of raw materials, semi-finished product fabrications, and transport expenditures in the construction phase. All these expenses influence the final thermo-ecological cost burdening the final useful product. This phase has a significant contribution in the case of processes that are based on renewable sources of energy. For instance, in the case of wind power, the plant thermo-ecological cost results mainly from expenses in construction phase.

2. Operational phase is defined as the period of time between the end of construction phase and the beginning of decommissioning phase. In processes utilising non-renewable resources, this phase is predominant in the cumulative consumption of natural resources, mainly energy carriers.

3. Decommissioning phase of plant concerns the period at the end of installation's life. In this phase, thermoecological cost results from expenditures for reclaiming or disposing of the system remains, and for example some expenditures for reclamation of terrain.

The general form of the objective function, in the case of thermo-ecological cost minimisation, takes into account the lifetime of a product, as it has been stated by J. Szargut and presented in (Szargut, 2005), also applied e.g. for investigation in work of Szargut and Stanek (2007). This function has the following form:

$$
\begin{aligned}
\Theta_{L C A}= & \tau_{n}\left(\sum_{j} \dot{G}_{j} \rho_{j}+\sum_{k} \dot{P}_{k} \zeta_{k}-\sum_{u} \dot{G}_{u} \rho_{i} s_{i u}\right) \\
& +\frac{1}{\tau}\left(\sum_{m} G_{m} \rho_{m}\left(1-u_{m}\right)+\sum_{r} G_{r} \rho_{r}\right)
\end{aligned}
$$

The presented formula expresses the yearly thermoecological cost of investigated useful product with inclusion of the entire lifetime (TEC-LCA) of this product. Equation (3) can be also applied in order to optimize construction and operational parameters of different resources of intensive systems. In this case the following condition:

$\Theta \rightarrow \min$.

should be fulfilled.

\subsection{Thermo-ecological assessment of rejection of harmful substances}

Fig. 3 presents the connections between $j^{\text {th }}$ productive process and rejections of harmful substance to the natural environment.

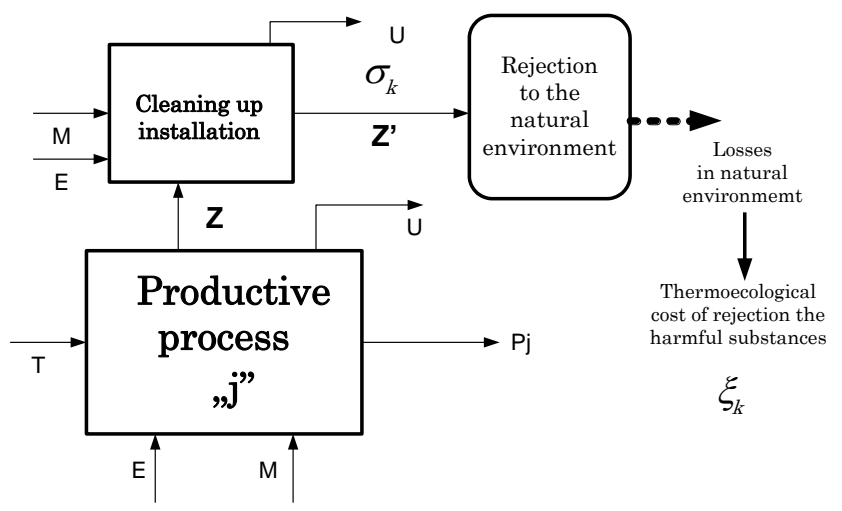

Figure 3. Rejection of harmful substances to natural environment.

Symbols in Fig. 3 concern: $E$ - energy, $M$ - raw materials or semi-finished products, $U$-by-products, $T$ - transport, $P$ - main product of $j^{\text {th }}$ productive process, $\boldsymbol{Z}$ - harmful waste products generated in $j^{\text {th }}$ productive process transferred to cleaning up the installation, and $\boldsymbol{Z}^{\prime}$ - harmful waste products rejected to the natural environment.

From the thermo-ecological point of view, this chain (Fig. 3) can be divided into two characteristic stages. The first stage encompasses the thermo-ecological cost resulting from the necessity of cleaning of harmful products of $j^{\text {th }}$ productive process while the second stage is the rejection of harmful substance $k$ to the natural environment. The environmental losses are caused by both of such phases. The first phase requires some exergy expenditure of natural resources to clean up of the stream $\boldsymbol{Z}$ (abatement cost (Valero \& Botero, 2002a)). The rejection of harmful substance causes environmental losses in the fields of human health, useful industrial and other manufactured products (machines, buildings, transportation equipment) and losses in agriculture and forestry. All of such losses require some additional resources expenditure to compensate them.

The thermo-ecological cost resulting from rejection of harmful substances to the natural environment can be evaluated by means of monetary indices of harmful impacts $w_{k}$ (Stanek, 2001; Szargut, 2005):

$$
\zeta_{k}=\frac{B w_{k}}{G D P+\sum_{k} P_{k} w_{k}}
$$


In addition to the thermo-ecological cost of harmful substances, we can also distinguish so-called "abatement costs" of harmful substances. Such a cost expresses the energy and material expenditures resulting from operation of cleaning-up installations. It can be obtained from the following simplified formula:

$$
\sigma_{k}=\frac{\sum_{j} G_{j k} \rho_{j}-\sum_{u} G_{u k} s_{i u} \rho_{i}}{G_{k}}
$$

Based on the thermo-ecological cost index $\zeta_{k}$ and the abatement cost $\sigma_{k}$, the sustainability factor for a cleaning installation can be defined as:

$$
r_{k}=\frac{\sigma_{k}}{\zeta_{k}}
$$

Table 3 presents calculation results of thermo-ecological cost $\zeta_{k}$, abatement cost $\sigma_{k}$ and the sustainability factor for the main pollutants.

Table 3. Comparison of abatement and thermo-ecological costs.

\begin{tabular}{cccc}
\hline $\begin{array}{c}\text { Harmful } \\
\text { substance }\end{array}$ & $\begin{array}{c}\text { Abatement } \\
\text { cost } \\
\mathrm{MJ} / \mathrm{kg}\end{array}$ & $\begin{array}{c}\text { Thermo-ecological } \\
\text { cost } \\
\mathrm{MJ} / \mathrm{kg}\end{array}$ & $\begin{array}{c}\text { Sustainability } \\
\%\end{array}$ \\
\hline $\mathrm{CO}_{2}$ & 4.4 & $==$ & $==$ \\
$\mathrm{SO}_{2}$ & 17.5 & 45.0 & 38.0 \\
$\mathrm{NO}_{\mathrm{x}}$ & 26.0 & 45.0 & 58.0 \\
dust & 0.5 & 9.5 & 5.0 \\
\hline
\end{tabular}

Cleaning of the waste product is profitable when the sustainability index is less than 1 . Presented results show that cleaning of flue gases from dust particles while using the electrostatic precipitator is relatively more efficient from the ecological point of view, in comparison to other pollutants taken into account. Because it is impossible to determine thermo-ecological cost of $\mathrm{CO}_{2}$ by means of monetary indices of harmful impact (eq. 5), only the method of abatement cost can be applied as an approximate method of evaluation of thermo-ecological cost of rejection of $\mathrm{CO}_{2}$ to the natural environment.

\section{Examples of Applications of Thermo-Ecology}

The presented theory of thermo-ecological cost can be applied to solve the following problems (Szargut, 2005):

1) Influence of operational parameters of energy and technological systems upon depletion of non-renewable natural resources,

2) Selection of the kind of technology that ensures minimal consumption of non-renewable natural resources,

3) Optimisation of design and operational parameters to ensure minimum depletion of natural resources,

4) Evaluation of harmful impacts of waste products,

5) Investigation of the influence of interregional exchange upon depletion of domestic natural resources,

6) Evaluation of the ecological harmfulness of particular useful goods in their whole life time (thermo-ecological life cycle analysis),

7) Comparison of sustainability of different useful products,
8) Determination of pro-ecological tax replacing existing PIT and VAT.

\subsection{TEC-LCA of useful heat}

In a paper, the thermo-ecological cost of selected heat sources, considering the entire life cycle, has been determined. The results are as follow (Stanek, 2009):

Solar collector $0.6 \mathrm{MJ}_{\mathrm{ex}} / \mathrm{MJ}_{\mathrm{q}}$,

Water boiler fed with gas $1.05 \mathrm{MJ}_{\mathrm{ex}} / \mathrm{MJ}_{\mathrm{q}},\left(\eta_{E k}=90 \%\right)$

Water boiler fired with coal $1.44 \mathrm{MJ}_{\mathrm{ex}} / \mathrm{MJ}_{\mathrm{q}}$, $\left(\eta_{E k}=\right.$ $80 \%)$

Central heating in Polish condition (without cogeneration) $1.3 \mathrm{MJ}_{\mathrm{ex}} / \mathrm{MJ}_{\mathrm{q}}$,

Cogeneration in Polish condition $0.94 \mathrm{MJ}_{\mathrm{ex}} / \mathrm{MJ}_{\mathrm{q}},\left(\eta_{\mathrm{CHP}}=\right.$ $0.85)$.

The presented results confirmed the favourable influence of cogeneration on savings of non -renewable natural resources.

Fig. 4 presents the structure of thermo-ecological cost of useful heat in the case of a boiler fired with gas in the case of solar collector (Stanek, 2009).

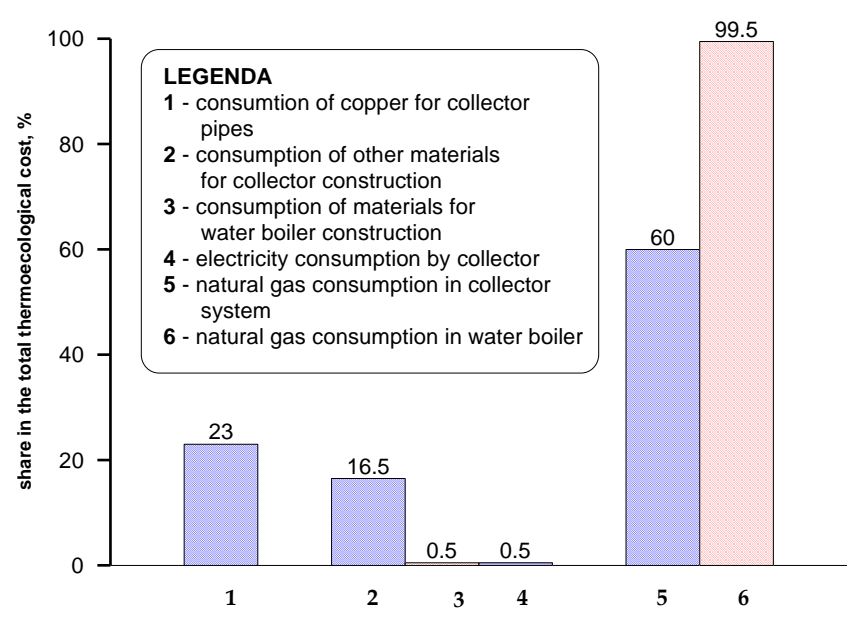

Figure 4. Structure of the thermo-ecological cost in whole life cycle-hot water.

In the case of heat production in a water boiler, the structure of the thermo-ecological cost is dominated by the consumption of natural gas and reaches approximately $99.5 \%$. For this reason, in systems based on the consumption of non-renewable fuels, we can estimate thermo-ecological indices basing mainly on fuel consumption. In these cases operational thermo-ecological cost dominates (Eq. 1). In the case of production of hot water in collector installation, it is necessary to take into account the whole operating life cycle (Eq. 3). The share of thermo-ecological cost of materials for construction of collector reaches $39.5 \%$. Where $23 \%$ represents the thermoecological cost of copper tubes. The share of consumption of gas in a peak heater reaches $60 \%$. Taking into account only the operational part of the thermo-ecological cost of systems, using partly renewable resources is not acceptable.

\subsection{Thermo-Ecological optimization}

If there is even only a slight possibility of exhaustion of natural non-renewable resources, then the minimization of the depletion of these resources should become a more and 
more important criterion during any operating system's construction.

Minimisation of thermo-ecological cost can concern both operational and constructional parameters. Thermodynamic optimization can be performed on a local or global scale (Bejan, 1996; Szargut, 2005). In this section it will be shown that local optimization (minimization of entropy generation or internal exergy losses) can lead to the wrong conclusion. For this purpose, a blast furnace has been investigated. Coke is the basic fuel for a blast-furnace. However, this fuel is characterised by a relatively high index of thermo-ecological cost (Table 1). Coke can be partly replaced in blast-furnace by injection of pulverized coal. The effect of replacement of coke by coal is presented in Fig. 5.

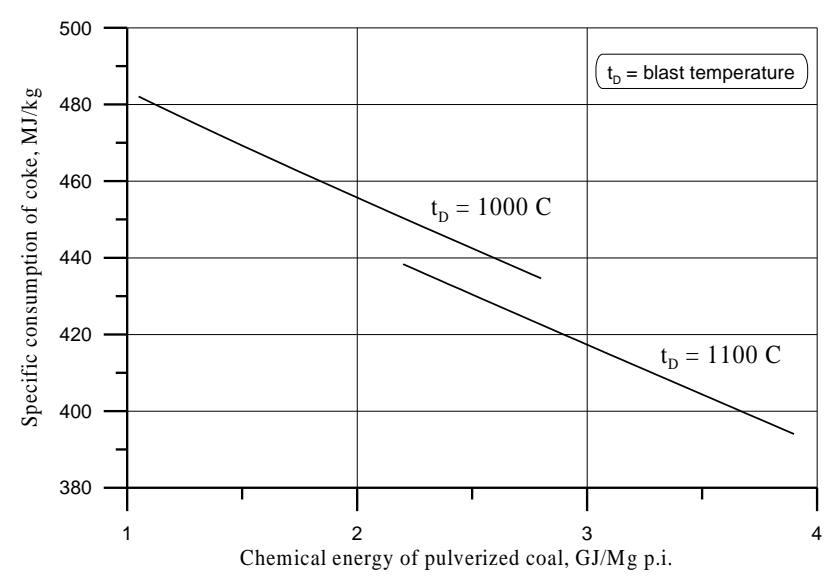

Figure 5. Specific consumption of coke in blast furnace.

A blast furnace is characterized by rather high exergy efficiencies reaching $70 \%$. Such high exergy efficiencies can be obtained because the processes of mass and heat exchange have a counter-current character in the blast furnace. Injection of cold coal destroys this phenomena and leads, of course, to the decrease of the blast furnace's exergy efficiency. This effect is presented in Fig. 6.

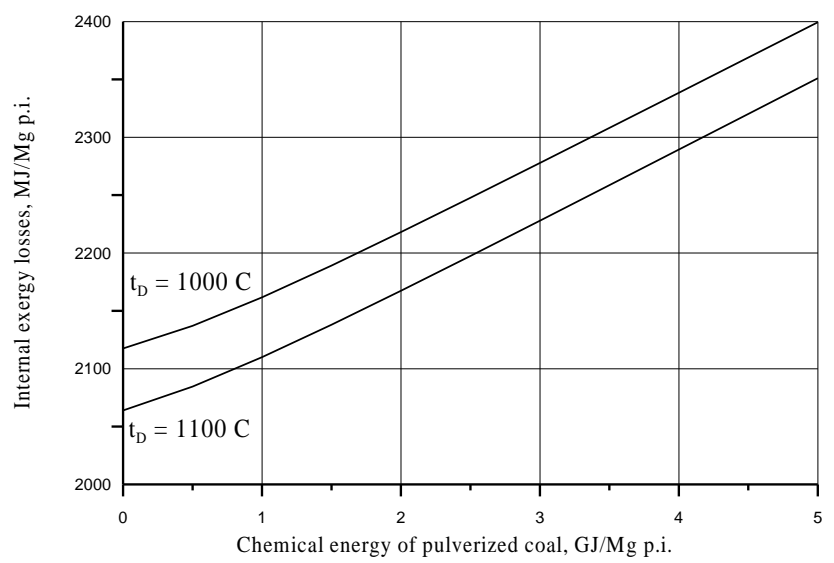

Figure 6. Internal exergy losses in blast furnace.

Taking into account the criterion of local minimisation of thermo-ecological cost, we reached from Fig. 6 the conclusion that the injection of coal is not-favourable. However, this statement is a wrong and misleading conclusion. Fig. 7 shows clearly that the thermo-ecological cost decreases with the increasing amount of injected coal.
We reach the savings in natural non-renewable resources not locally but in other points of complex systems of processes connected with the blast process. The consumption of coke with a rather high sustainability index has been replaced by coal of relatively lower sustainability index.

The presented results of the thermo-ecological analysis show clearly that for the presented minimization, entropy generation criterion is not correct. In the systems with strong connections between particular processes the cumulative calculus should be taken into account. Taking into account minimization of non-renewable resources consumption, a criterion similar to thermo-ecological cost presented in this paper is necessary.

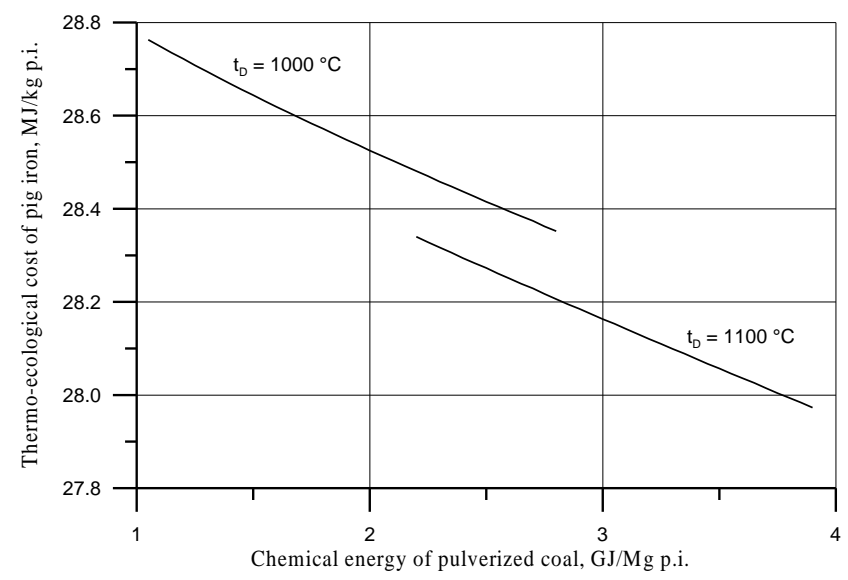

Figure 7. Influence of injection of pulverised coal into blast furnace on the thermo-ecological cost of pig iron.

\section{Summary}

In this paper the theory of thermo-ecological cost is presented and discussed. Example calculations illustrating possibilities of application of thermo-ecology have been included. The author showed selected results of calculation of thermo-ecological cost and sustainability factor of fuels and non-energetic material. The sustainability factor has been useful for selection of production technology. Presented results confirmed that coke should be eliminated as often as possible. Additionally, the application of thermo-ecological cost for evaluation of the whole life cycle has been additionally presented, and selected results have been included. This part shows that it is necessary to take into account the LCA methodology while analysing processes based on the consumption of renewable resources. The problem of application of thermo-ecological cost for minimization of depletion of non-renewable resources has been presented. Example results of calculation of thermo-ecological cost of pig iron has been also evaluated. In this part, it was stated and confirmed that local optimization does not always lead to the correct conclusion.

\section{Acknowledgments}

The paper has been prepared within the RECENT project (REsearch Center for Energy and New Technologies) supported by 7 th Framework Programme, Theme 4, Capacities. 


\section{Nomenclature}

$a_{i j} \quad$ coefficient of the consumption of the $i$-th product per unit of the $j$-th major product

$a_{r j} \quad$ coefficient of the consumption of the $r$-th imported product per unit of the $j$-th major product

$b_{i} \quad$ specific exergy of the $i$ th good

$b_{s j} \quad$ exergy of the sth non-renewable natural resource immediately consumed in the process under consideration per unit of the $j$ th product

$B$ exergy extracted per year from the domestic nonrenewable natural resources

$f_{i j} \quad$ coefficient of by-production of the $i$-th product per unit of the $j$-th major product

GDP Gross Domestic Product

$\dot{G}_{j} \quad$ nominal flow rate of the $j$ th major product

$\dot{G}_{u} \quad$ nominal flow rate of the useful uth by-product

$G_{m} \quad$ consumption of mth material or energy carrier used for construction of installation

$p_{\mathrm{kj}} \quad$ amount of the kth aggressive component of waste products rejected to the environment per unit of the jth product

$P_{k} \quad$ annual amount of kth waste product

$\dot{P}_{k} \quad$ nominal flow rate of the kth deleterious waste product rejected to the environment

$r_{i} \quad$ sustainability index of ith good

$s_{i u} \quad$ replacement ratio in units of the ith replaced product per unit of the uth by-product

$u_{m} \quad$ expected recovery factor of the mth material

$w_{k} \quad$ monetary factor of harmfulness of $k$ th substances

$z_{\mathrm{lj}} \quad$ amount of the lth aggressive component of waste products entering the cleaning installation

\section{Greek letters}

$\rho_{i} \quad$ thermo-ecological cost of the $i^{\text {th }}$ product

$\rho_{m} \quad$ thermo-ecological cost of $m^{\text {th }}$ material or energy carrier used for construction of installation

$\rho_{r} \quad$ specific thermo-ecological cost of the $r^{\text {th }}$ imported good

$\tau \quad$ nominal life time of installation

$\tau_{n} \quad$ annual operation time with nominal capacity $\zeta_{k} \quad$ cumulative exergy consumption of non-renewable resources due to the emission of unit of the $k^{\text {th }}$ waste product

$\sigma_{k} \quad$ cumulative exergy consumption of non-renewable resources due to the removing of $k^{\text {th }}$ aggressive product from wastes

\section{References}

Bejan A., Tsatsaronis G. (1996). Moran M. J., Thermal design and optimisation. J. Wiley.

Finneveden G., Ostlund P. (1997). Exergies of natura resources in life-cycle assessment and other applications, Energy, Vol. 22, No. 9, 923-931.

Sciubba, E. (2001). Beyond thermoeconomics? The concept of Extended Exergy Accounting and its application to the analysis and design of thermal systems. Exergy Int. J., Vol.1, 68-84.

Stanek W. (2001). Iterative Method To Evaluate the Ecological Cist of Imported Goods. International Journal of Thermodynamics, Vol. 4 (No. 4), 191-198.

Szargut J., Ziębik A., Stanek W. (2002). Depletion of the Unrestorable Natural Exergy Resources as a Measure of the Ecological Cost, Energy, Conversion and Management 42, 1149-1163.

Szargut J. (2005). Exergy method, technical and ecological applications. Southampton, Boston: WIT Press.

Szargut J., Stanek W. (2007). Thermo-ecological optimization of a solar collector. Energy 32, 584-590.

Valero A., Botero E. (2002a), An assessment of the Earth's clean fossil exergy capital based on Exergy Abatement Cost. Proc. Conf. ECOS'2002, Berlin, 151-157.

Valero A., Botero E. (2002b). An exergetic assessment of natural mineral capital (1): Reference environment, a thermodynamic model for $s$ degradated, Proc. Conf. ECOS 2002, Berlin, 54-61.

Wall, G., Gong M. (2001). On exergy and sustainable development, Exergy Int. J., Vol.1, 128-145.

Stanek W. (2009). Method of evaluation of ecological effects in thermal processes with the application of exergy analysis. Silesian University of Technology Press (in Polish). 